Original article

\title{
The role of maternal infectious diseases during pregnancy in the etiology of schizophrenia in offspring
}

\author{
G Stöber, E Franzek, H Beckmann \\ Department of Psychiatry, University of Wuerzburg, Fuechsleinstrasse 15, Wuerzburg W-8700 Germany
}

(Received 19 February 1992; accepted 1 June 1992)

\begin{abstract}
Summary - In 55 chronic schizophrenics, the occurrence of infectious diseases during their mothers' pregnancies was investigated. Different psychiatric diagnostic systems were compared. Infections were reported by the mothers of familial and sporadic DSM III-R schizophrenics in equal proportion. However, applying Leonhard's classification, the frequency of infections was found to be significantly increased in 'systematic' schizophrenia (mainly exogenously induced in the view of Leonhard) compared to 'unsystematic' schizophrenia (mainly genetically determined according to Leonhard's findings). Most of the infections occurred during the second trimester (nine out of 13). Thus, in the 'systematic' forms of schizophrenia (low genetic loading), maternal infections in this crucial period of neurodevelopment would appear to be important causative factors in the cytoarchitectural deviance detected in the central nervous system of schizophrenics.
\end{abstract}

maternal infection / pregnancy / schizophrenia / familial-sporadic concept / Leonhard classification

\section{Introduction}

Schizophrenia is postulated to be an etiologically heterogeneous disorder that emerges from an interaction of genetic and environmental factors (Wynne et al, 1978). The winterbirth seasonality which is often found in schizophrenics (Bradbury and Miller, 1985; Franzek and Beckmann, in press) draws attention to the seasonal prevalence of various bacterial and viral infectious diseases as presumed environmental factors (Watson et al, 1984; Torrey et al, 1988). Mednick et al (1988) were the first to find a strong relationship between the influenza A epidemic of 1957 and schizophrenia in adulthood. The offspring of women, exposed to this epidemic during the mid-trimester of gestation, subsequently had a higher risk of developing schizophrenia.

It is widely accepted that genes contribute to the etiology of schizophrenia (Gottesmann and Shields, 1982; Kringlen, 1990). However, the modes of transmission remain elusive, despite modern diagnostic criteria (WHO, 1979; APA, 1987). Within these classification systems, a positive family history of schizophrenia or related disorders in the pedigree, signifies high genetic risk with familial transmission (Tsuang et al, 1985). The absence of schizophrenia among relatives indicates the sporadic, mainly environmentally induced group (Kendler and Hays, 1982). This familial/sporadic distinction is assumed to be a useful strategy in schizophrenia research (Murray and Reveley, 1985; Lewis et al, 1987). Another approach in the classification of schizophrenia was advanced by Karl Leonhard (Fish, 1962; Hamilton, 1976; Astrup, 1979; Leonhard, 1979; Ban, 1982). Leonhard divided the entire disease into distinct subgroups, based on symptomatology, course and outcome. As an essential result of this approach he postulated two main categories: systematic and unsystematic forms. Subsequently, he investigated the inheritance of each of these categories. High family loading of psychoses was evident within the unsystematic forms. In contrast, almost no positive family history appeared in the systematic forms. Based on this significantly different heredity, Leonhard (1980) designated the unsystematic forms as being mainly genetically determined and the systematic forms as being sporadic, environmentally - induced forms. 
Table I. Demographic and clinical characteristics of patients and age of their mothers at the time of the interview with regard to the various diagnostic groups. (Using $t$-test no significant differences were obvious between any of the diagnostic groups.)

\begin{tabular}{lccccc}
\hline & $\begin{array}{c}\text { Total sample } \\
(\mathrm{n}=55)\end{array}$ & $\begin{array}{c}\text { Familial } \\
(\mathrm{n}=19)\end{array}$ & $\begin{array}{c}\text { SSM III-R } \\
\text { Sporadic } \\
(\mathrm{n}=36)\end{array}$ & $\begin{array}{c}\text { Unsystematic } \\
(\mathrm{n}=32)\end{array}$ & $\begin{array}{c}\text { Leonhard criteria } \\
\text { Systematic } \\
(\mathrm{n}=23)\end{array}$ \\
\hline Patients' age at study & $35.8 \pm 9.12$ & $36.2 \pm 9.72$ & $35.6 \pm 8.94$ & $36.6 \pm 8.82$ & $34.8 \pm 9.63$ \\
Age at first & & & & & \\
admission & $22.2 \pm 6.65$ & $20.9 \pm 8.35$ & $22.9 \pm 5.56$ & $22.7 \pm 5.97$ & $21.5 \pm 7.58$ \\
Duration of illness & $17.8 \pm 10.04$ & $17.6 \pm 10.59$ & $17.9 \pm 9.71$ & $16.0 \pm 8.72$ & $20.2 \pm 11.39$ \\
Sex (female/male) & $13 / 42$ & $6 / 13$ & $7 / 29$ & $8 / 24$ & $5 / 18$ \\
Mothers' age at study & $64.7 \pm 9.27$ & $63.5 \pm 10.14$ & $65.4 \pm 8.83$ & $64.4 \pm 9.62$ & $65.1 \pm 8.95$ \\
\hline
\end{tabular}

The purpose of the present study was to investigate in retrospect the occurrence of infectious diseases during pregnancy by comparing the following diagnostic systems: the familial/sporadic strategy in DSM

Subjects and methods

Starting in 1990, mothers of chronic schizophrenics were interviewed to investigate in retrospect various adverse events which had occurred during pregnancy, delivery, and the postnatal period and their relation to the develop-
ment of schizophrenia. In this paper we report on the ment of schizophrenia. In this paper we report on the
preliminary data about the occurrence of maternal infections during pregnancy.

Schizophrenic patients whose mothers were alive and
tions during pregnancy willing to be interviewed were drawn from patients at the Department of Psychiatry at Wuerzburg University and from the State Hospital Lohr/Main. The data of 55 chronic schizophrenics ( 12 women, 43 men) have so far criteria of chronic schizophrenia according to DSM III$\mathrm{R}$ and to the Leonhard classification. It should be emphasized here that Leonhard's criteria for inclusion ar much more restrictive than those of DSM III-R. On the basis of all avallable data and of personal examination, mann, E Franzek) working independently of each other. Both are experienced in DSM III-R and the Leonhard classification. In a recent study with chronic schizophrenics, they reached a coefficient of agreement (Cohen's kap pa) of 0.88 within the Leonhard classification (Franzek and Beckmann, 1991). All the patients were clearly allosystematic or systematic forms (Leonhard). Table I shows important demographic and clinical data of the $55 \mathrm{pa}$ tients as a whole and after separating into the diagnostic subsamples and the mean age of their mothers at the time of the interview.

diagnoses (systematic $v_{S}$ unsystematic schizophrenia) were established by taking into accoun schizophrenia, the acute symptomatology is usually polymorphous with a wide range of symptoms and remission are the rule. They lead to residual states of varying degrees systematic schizophrenias begin insidiously and take chronic non-remitting course. They always lead to sever defective states and no marked change in the symptom and signs takes place once the residual syndromes are established. The latter are meticulously elaborated by LeonBan, 1982. Franzek and Beckmann, in press) A familia form of schizophrenia (DSM III-R) was presumed when relatives. The family history data were taken from the hospital records of the patients containing information from their family doctors, reliable relatives, and acquain-
tances.

Familial/sporadic distinction according to DSM

The 55 patients had a total of 38 relatives who had undergone psychiatric hospitalisation. Hospital records wer available for all of these relatives. Twenty-six of them out of the 55 index patients. This results in 19 famila

Leonhard classification

Twenty-three systematic and 32 unsystematic forms H Beckmann). mily history was not considered. In the unsystematic schizophrenia was present in first and/or second degree were diagnosed as schizophrenics and were related to 19 (diagnosed independently of each other by E Franzek and
Genetic risk supposed to be similar in both classification systems

Thirteen of the patients who were diagnosed as un systematic schizophrenics (mainly genetically determin cond degree relative (familial form according fo DSM or se$R)$. This subsample of patients was defined as the 'high genetic risk group

tiveventeen of the patients without a schizophrenic relative (sporadic form) fulfilled the diagnostic criteria of mined according to Lnia (mainly environmentally deter 'low genetic risk group'. Wenar (1963), Joffe and Grisso (1985), and O'Callaghan et al (1990) likewise emphasized that mothers reliably and accurately recall the period of gestation and delivery and that passing of time does not diminish this a retrospective study design. We have developed a highly structured questionnaire
(Stöber in propation) (Stöber, in preparation). All questions concerning course of pregnancy, delivery and post-natal development were asked person-to-person and notable events were written currence of infectious diseases during placed on the occontext, the first question was: 'Did you suffer from any infectious diseases during pregnancy?' Then the interviewer regularly asked if the subject had suffered from the

nasal catarrh or cough lasting for at least 2 weeks; com-
mon cold; bronchitis; influenza; tis media; tonsillitis; gastroenteritis; urinary infection (cystitis, pyelonephritis); localized pyogenic infections (abscess, phlegmone); salmonellosis; rubella; measles: mumps; varizella; (ictero-)hepatitis; herpes zoster; venera If any of these infections wingitis; and sepsis.

(G Stöber) exactly noted its duration and whe interviewer during the gestational period (month and trimester). The questionnaire was carried out on 20 control mothers (mean age 65.7 years) with physically and mentally healthy children (mean age 32.4 years). In the controls, pregnancy, delivery, and post-natal development The mothers of schizop

renic patients were contacted pointed out to them. None of them refused a personal visit. Every interview took about $2 \mathrm{~h}$.

The interviewer (G Stöber) was not aware of the unsystematic/systematic schizophrenia or /sporadic and ry. He was not permitted to ask a question about this is55 during the interview. This rule was applied until all

5 mothers had been interviewed.

Results

Thirteen out of $55(24 \%)$ mothers of adult schizophrenics recalled an infectious disease during
Table II. Types of maternal infections $(n=13)$ and their allocation to the three trimesters of gestation in the entire sample.

\begin{tabular}{llcc}
\hline $\begin{array}{l}\text { Type of } \\
\text { infection }\end{array}$ & Trimester of gestation \\
\hline Influenza & 1 & II & III \\
Cold with fever & 1 & 4 & 0 \\
Pyonephritis & 0 & 2 & 0 \\
Otitis media & 0 & 1 & 1 \\
Sinusitis & 1 & 0 & 0 \\
Tonsillititis & 0 & 1 & 0 \\
Sepsis & 0 & 0 & 1 \\
\hline
\end{tabular}

pregnancy, compared to four out of 20 contro mots (20). In comparison to trimesters I and II, the frequency of maternal infectious disease was significantly increased in trimester II in the patents group $\left(\chi^{2}=7.54, \mathrm{df}=2, P<0.05\right)$. No fifth mon the sifnificant $\left(2^{2}\right.$ gestation. This was also statistically As shown in table II, $\mathrm{df}=8, P<0.02$, fig 1$)$ of the respiratory tract. Six out of the 13 mothers $(46 \%)$ remembering an infectious disease reported influenza or the common cold with fever at midgestation.

In the total sample, there were no substantial differences in the frequency of maternal infection between the familial and sporadic forms of DSM III-R schizophrenia (fig $2 \mathrm{~A}$ ). In contrast, taking the Leonhard classification as a diagnostic basis, highly significant differences occurred (fig 2B). Only $6.3 \%$ of the unsystematic forms, but $47.8 \%$ of the systematic forms were associated with maternal inFigure $3=15.2, \mathrm{df}=1, P<0.001)$.

Figure 3 shows the subsample of patients ( $\mathrm{n}=$ in both classification systems. risk group (ie diagnosis of unsystematic schizophre nia and of familial schizophrenia) mothers did not report any infection during pregnancy. In contrast $41 \%$ of mothers in the low-genetic risk group (ie diagnosis of systematic and sporadic schizophrenia) recalled an infection during pregnancy. This difference was also significant $\left(\chi^{2}=4.87, \mathrm{df}=1\right.$, $P<0.05)$

\section{Discussion}

The relationship of maternal infectious diseases during pregnancy to the development of schizophrenia 


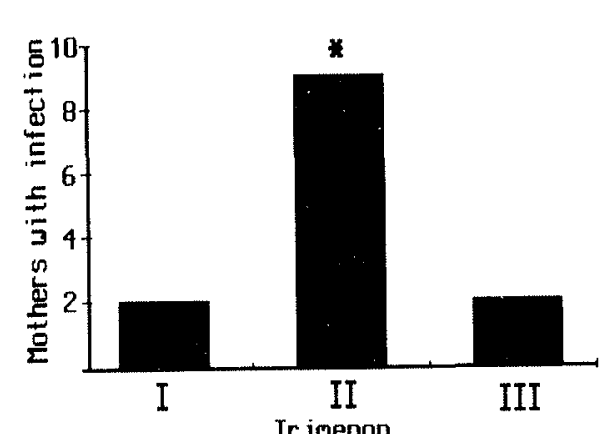

B)

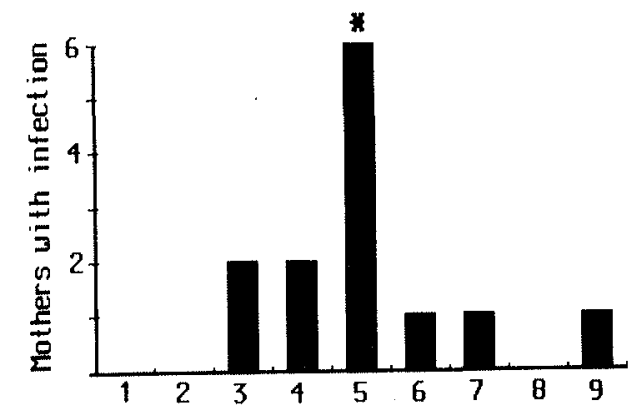

Month of gestation

Fig 1. Number of infections in the total sample $(n=13)$ and
their distribution between trimester $(\mathbf{A})$ and between month of gestation (B). In trimester II, maternal infectious diseases were significantly higher than in trimester I and $1 \mathrm{II}(P<0.05$, df $=$
$2, \chi^{2}=7.54$ ). With respect to months of gestation, there was a significantly higher number of maternal infections in the ifth
month $\left(P<0.02, \mathrm{df}=8, \chi^{2}=19.55\right)$ compared to the other months.

in adulthood is a matter of controversy. Based on population data, several research groups drew attention to the fact that the risk of schizophrenia is higher for those who were in mid-gestation during the influenza A epidemic of 1957 (Mednick et al, 1988; Barr et al, 1990; O Callaghan et al, 1991). birth complications had ever demonstrated an increased frequency of prenatal infections among mothers of a representative sample of schizophrenics (McNeil, 1987). With respect to maternal infectious diseases during pregnancy, 55 mothers of adult chronic schizophrenics were interviewed using a highly structured questionnaire. Twenty-four percent of the mothers reported an infection during pregnancy and in most cases the infection was of the respiratory tract. Contrary to Watson et al (1984) and Torrey et al (1988), we did not find any
case of diphtheria, scarlet fever, rubella, varicella

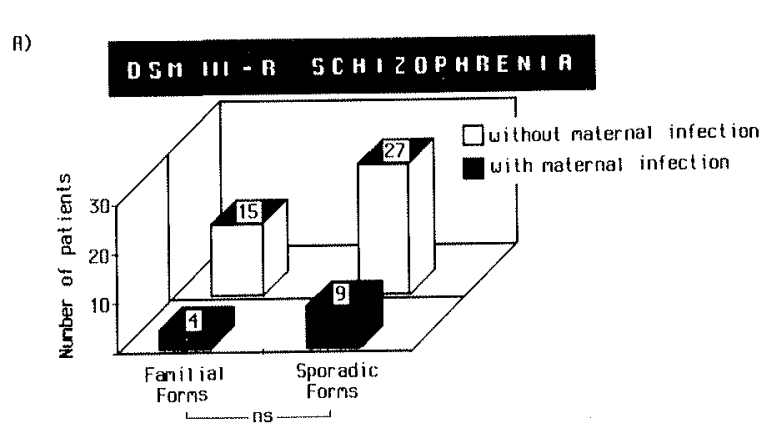

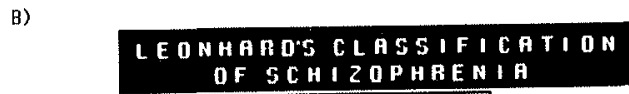

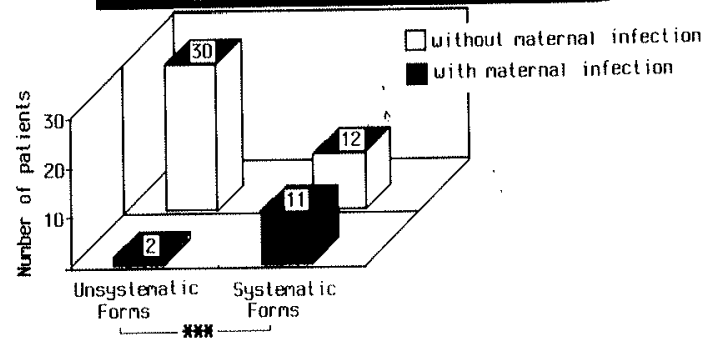

Fig 2. Maternal infections co-varied with familial/sporadic distinction in DSM III-R (A) and with Leonhard's main categories (B) of schizophrenia. No substantial difference was found in
familial/sporadic distinction (A: ns, df $=1, \chi^{2}=0.437$. In the Leonhard classification was highly significant (B: $P<0.001$ $\left.\mathrm{df}=1, \chi^{2}=15.2\right)$. Here, materna

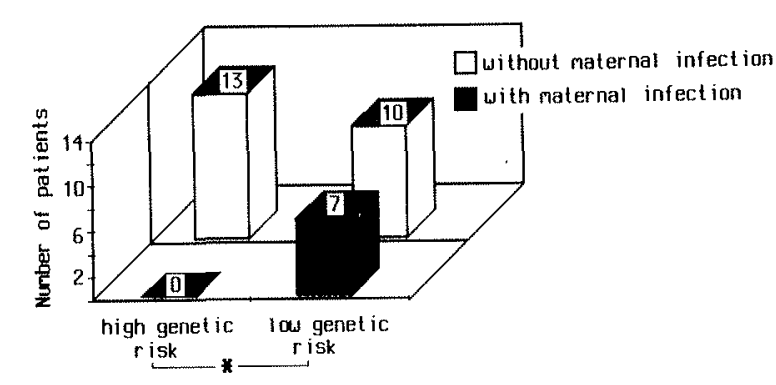

Fig 3. Subsample of patients $(n=30)$ that had an equal genetic
risk in both DSM III-R and Leonard's classification. risk in both DSM III-R and Leonard's classification. The high familial schizophrenia in DSM III-R but also those of Leonhard' unsystematic schizophrenia. No mother out of this group ( $n$ 13) had suffered from an infectious disease. The low risk grou schizophrenia in DSM III-R and Leonhard's systematic forms With respect to the occurrence of maternal infectious diseases during pregnancy, there was a significant difference between the
low risk and the high risk group $\left(P<0.05, \mathrm{df}=1, \chi^{2}=4.87\right)$. or measles (table II). Sepsis as a very serious illness occurred in only one case $(1.8 \%)$ ) which is in accordance with the findings of DeLisi et al (1988). In cond O'Callat ot al (1991), we found a (199) cantly increased number of maternal infections in mid-trimester and in particular in the fifth month of gestation in the total sample.

Using the familial/sporadic concept of Lewis et al (1987), an equal proportion of infections occurred in both groups. Within the Leonhard classification, however, maternal infections were rarely found in patients with unsystematic schizophrenia which is mainly transmitted genetically, according to Leonhard's findings. On the contrary, they were highly significantly associated with the systematic (ie nongenetic) schizophrenics. This significant association persisted in a distinct subsample of patients, labeled as 'low-genetic risk group' (fig 3), ie fulfilling the definition of sporadic schizophrenia (Lewis et al, 1980). Interestingly in the 'high-genetic risk roup', ie patients not only with familial but also unsystematic schizophrenia maternal infections were not traceable at all. This indicates that maternal infections did not substantially contribute to the etiology of genetically vulnerable forms of schizophrenia. However, in the 'low-genetic risk group' (not only systematic but also sporadic schizophrenia, fig 3) and in particular in Leonard's systematic schizophrenics (fig 2B), maternal infections during gestation seem to be of great etiological importance. Nearly $50 \%$ of the mothers in these groups unequivocally recalled an infectious disease between disturba. This stresses that there is a link and the development of schizophrenia in adulthood (Jakob and Beckmann, 1986; Falkai et al, 1988; Arnold et al, 1991; Beckmann and Jakob, 1991). Jakob and Beckmann (1986) reported definite cytoarchitectural deviance in the rostral entorhinal region of the parahippocampal gyrus in postmortem studies of schizophrenics. This was explained by a disruption of neuronal migration. In particular during the second trimester of gestation, neurons migrate from the ventricular zone to their predetermined positions within the central nervou ystem (Rakic, 1978, 1988). For this reason, ou period suggest that maternal infection during thi turbance of neurodevelopment and that there is positive correlation only to forms with low gentic loading and in particular to the systematic forms of schizophrenia in Leonhard's concept.

The findings shed new light on the heterogenous etiology of schizophrenic syndromes and on the validity of different diagnostic and nosologica

References

American Psychiatric Association (1987) Diagnostic and revised. APA, Washington DC

Arnold SE, Hyman BT, van Hoesen GW, Damasio AR (1991) Cytoarchitectural abnormalities of the entorhnal cortex in schizophrenia. Arch Gen Psychiatry 48,

Strup C (1979) The Chronic Schizophrenias. Oslo,

hard's classification. Compr Psychiatry 23, 155-165 arr CE, Mednick SA, Munk-Jorgensen P (1990) Exposure to influenza epidemics during gestation an chiatry 47, 869-874

Beckmann H, Jakob H (1991) Prenatal disturbances of nerve cell migration in the entorhinal region: a common vulnerability factor in functional psychoses? Neural Transm 84, 155- 164

Bratch Tizh i Psychol Bull 98, $569-594$ DeLisi LE, Dauphinais ID, Gershon ES (1988) Perinatal complications and reduced size of brain limbic struc-
tures in familial schizophrenia. Schizophr Bull 14,

kai P, Bogerts B, Rozumek M (1988) Limbic pathology in schizophrenia: The entorhinal region - a morphometric study. Biol Psychiatry 24, 515-521
Fish FJ (1962) Schizophrenia. Wright, Bristol

Franzek E, Beckmann H (1991) Syndrom - und Synptomentwicklung schizophrener Langzeitverläufe. Ner-

H (1992) Season-of-birth effect of schizophrenia. Biol Psychiatry (in press)

ranzek E, Beckmann H (1992) Schizophrenia: Not a disease entity? A study of 57 longterm hospitalized chronic schizophrenics. Eur J Psychiatry (in press) Thia. The Hamilton M (1979) Fish's Schizophrenia. Wright,

Jacob H, Beckmann H (1986) Prenatal developmental disNeural Transm 65,303-326

hospital records with retrospective interviewing. $J$ Bio

Soc Sci 17, 113- 119
Kendler KS, Hays P (1982) Familial and sporadic schizophrenia: a symptomatic, prognostic and 
Kringlen E (1990) Genetic aspects of schizophrenia with special emphasis on twin research. In: Etiology of Mental Disorder (Kringlen E, Lavik NJ, Torgersen S, eds) University of Oslo, Oslo, 63-80

Leonhard K (1979) The classification of endogenous psychoses. Irvington, New York

Leonhard K (1980) Contradictory issues in the origin of schizophrenia. Br J Psychiatry 136, 437-444

Lewis SW, Reveley AM, Reveley MA, Chitkara B, Murray $\mathrm{RM}$ (1987) The farnilial/sporadic distinction as a strategy in schizophrenia research. Br J Psychiatry 151, $306-313$

McNeil TF (1987) Perinatal influcences in the development of schizophrenia. In: Biological Perspectives of Schizophrenia (Helmchen H, Henn FA, eds) Wiley, Chichester

Mednick SA, Machon RA, Huttunen MO, Bonett D (1988) Adult schizophrenia following prenatal exposure to an influenza epidemic. Arch Gen Psychiatry 45, $189-192$

Murray RM, Reveley AM (1985) Towards an etiological classification of schizophrenia. Lancet 1023-1026

O'Callaghan E, Larkin C, Waddington JL (1990) Obstetric complications in schizophrenia and the validity of maternal recall. Psychol Med 20, 89-94

O'Callaghan E, Sham P, Takei N, Glover G (1991)
Schizophrenia after prenatal exposure to 1957 A2 influenza epidemic. Lancet $1248-1249$

Rakic P (1978) Neuronal migration and the contact guidance in the primate telencephalon. Postgrad Med $J 54,25-40$

Rakic P (1988) Specification of cerebral cortical areas. Science $241-174$

Torrey EF, Rawlings R, Waldman IN (1988) Schizophrenic births and viral diseases in two states. Schizophr Res $1,73-77$

Tsuang MT, Kendler KK, Gruenberg AM (1985) DSM III schizophrenia: Is there evidence for familial transmission? Acta Psychiatr Scand 71, 77-83

Watson CG, Kucala T, Tilleskjor C, Jakobs L (1984) Schizophrenic birth seasonality in relation to the incidence of infectious diseases and temperature extremes. Arch Gen Psychiatry 41, 85-95

Wenar C (1963) The reliability of developmental histories. Psychosom Med 25, 505-509

World Health Organisation (1979) Mental disorders: Glossary and guide to their classification in accordance with the ninth revision of the international classification of diseases. WHO, Geneva

Wynne LC, Cromwell RL, Matthysse S (1978) The Nature of schizophrenia: New Approaches to Research and Treatment. John Wiley, New York 